\title{
Formulation of Dispersed Gliclazide Powder in Polyethylene Glycol-Polyvinyl Caprolactam- Polyvinyl Acetate Grafted Copolymer Carrier for Capsulation and Improved Dissolution
}

\author{
Ather Ahmed Mahdi Dukhan', Nursazreen Amalina', May Kyaw Oo', Pinaki Sengupta,,2, \\ Abd Al Monem Doolaanea', Khater Ahmed Saeed Aljapairai ${ }^{1}$, Bappaditya Chatterjee ${ }^{1, *}$ \\ ${ }^{1}$ Pharmaceutical Technology, Kulliyyah of Pharmacy, International Islamic University Malaysia, 25200, Kuantan, MALAYSIA. \\ ${ }^{2}$ National Institute of Pharmaceutical Education and Research, Ahmedabad, Gujarat, INDIA.
}

\begin{abstract}
Background: Oral bioavailability of gliclazide, a hypoglycemic drug, is hindered by its low aqueous solubility. Improvement of solubility will enhance dissolution rate and in turn the bioavailability. This research aimed to formulate the solid dispersed gliclazide using a novel polyethylene glycol-polyvinyl caprolactam-polyvinyl acetate grafted copolymer (Soluplus ${ }^{\circledR}$ ) as carrier to enhance in-vitro dissolution and to study drug-carrier physical interaction. Method: Final solid dispersion (SDGLC) containing drug:carrier $(1: 8 \mathrm{w} / \mathrm{w})$ was prepared by solvent evaporation after drug-polymer miscibility study. The SDGLC powder was characterized by differential scanning calorimetry (DSC), attenuated total reflectance infra-red spectroscopy (ATR-IR), powder X-ray diffraction (PXRD), and scanning electron microscopy (SEM). SDGLC powder was filled in gelatin capsule after flowability and moisture analysis followed by assay, disintegration and in-vitro dissolution study. Results: Miscibility study showed negative values of free energy transfer indicating spontaneous solubilization of drug with increase in carrier concentration. Absence of sharp melting peak in SDGLC was observed by DSC. Reduced peak intensity at specific $2 \theta$ values in PXRD indicates loss of crystallinity in solid dispersion. Interaction to form $\mathrm{H}$-bond between gliclazide and Soluplus ${ }^{\circledR}$ was evidenced by ATR-IR. SDGLC filled capsule resulted in $20 \%$ improved dissolution (approximately $20 \%$ higher) in $0.1(\mathrm{~N})$ $\mathrm{HCl}$ and phosphate buffer $\mathrm{pH} 7.4$ compared to physical mixture (gliclazide-Soluplus ${ }^{\circledR}$ ) containing capsule. Conclusion: Soluplus ${ }^{\circledR}$ effectively enhanced gliclazide solubility in solid dispersed state and SDGLC powder filled capsules could provide $\mathrm{pH}$ independent and improved in-vitro dissolution for gliclazide.
\end{abstract}

Key words: Solid dispersion, Gliclazide, Soluplus ${ }^{\circledR}$, Improved dissolution, Amorphous.

\section{INTRODUCTION}

Limited aqueous solubility of active pharmaceutical ingredients (API) can delay the dissolution which may eventually lead to poor bioavailability. Various approaches have been adopted to address poor dissolution issue which include chemical modification of drug such as salt formation, ${ }^{1}$ prodrug formation $^{2}$ or physical modification of drug such as mechanical micronization, ${ }^{3}$ micro or nano scale particle formation ${ }^{4}$ and solid dispersion. ${ }^{5}$ Despite some stability related drawbacks such as lack of adequate scalcal stability and processing difficulties of amorphous materials, solid dispersion is one the prevalent approaches practiced for pharmaceutical formulation development with poor soluble

API. ${ }^{6-7}$ Solid dispersed formulation is usually a binary or ternary system where drug able methods, poor physical and chemi-
Submission Date: 04-01-2018; Revision Date: 17-05-2018; Accepted Date: 14-08-2018

DOI: 10.5530/ijper.52.4s.100 Correspondence: Dr. Bappaditya Chatterjee, Assistant Professor, Pharmaceutical Technology Department, Kulliyyah of Pharmacy, International Islamic University Malaysia, 25200, Kuantan, MALAYSIA. Phone: +60 1115484450 E-mail: bdpharmaju@gmail. com

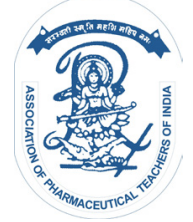

www.ijper.org 
is dispersed in a hydrophilic polymeric carrier such as polyvinyl pyrrolidone (PVP K30), poloxamer, poly ethylene glycol, hydroxyl propyl methyl cellulose (HPMC) or in the

form of solid solution, eutectic mixtures or amorphous precipitates. ${ }^{7}$

Polyethylene glycol-polyvinyl caprolactam- polyvinyl acetate grafted copolymer (Soluplus ${ }^{\circledR}$ ) is a newer addition to the polymeric solubilizer family with some distinct features and advantages. It possesses a bifunctional character; hence it may act as matrix forming agent for solid solution as well as solubilizer for poor soluble drug. Soluplus ${ }^{\circledR}$ was observed to be highly capable in solubility enhancement of Biopharmaceutics Classification System (BCS) class II and class IV drugs. ${ }^{8}$ Due to hydrophilic and non-ionic nature, its solubility does not change with changing $\mathrm{pH}$ of gastro-intestinal tract. ${ }^{9}$ With its water solubility and comparatively low glass transition temperature (approximately $70^{\circ} \mathrm{C}$ ), Soluplus ${ }^{\circledR}$ had been employed in previous studies for different method of solid dispersion preparations such as hot melt extrusion for Lafutidine ${ }^{10}$ or solvent evaporation for atorvastatin. ${ }^{11}$

Gliclazide (GLC), a second-generation sulphonyl urea compound is used to treat type II diabetes mellitus. Belonging to BCS class II, GLC has poor solubility but high permeability and its oral bioavailability depends on its dissolution in the gastrointestinal tract. ${ }^{12}$ Solid dispersion of GLC was developed by various researchers using different carriers such as polyvinyl pyrrolidone, Mannitol, polyethylene glycol and so on. ${ }^{12-13}$ But there was no report published on rendering GLC solid dispersion using novel polymeric solubilizer such as Soluplus ${ }^{\circledR}$.

The aim of this study was to formulate a GLC-Soluplus ${ }^{\circledR}$ solid dispersed powder and evaluate its solid state characteristics. Solid dispersion was prepared by solvent evaporation method and the dispersed powder was characterized by differential scanning calorimetry (DSC), attenuated total reflectance infra-red spectroscopy (ATR-IR), powder X-ray diffraction (PXRD), and scanning electron microscopy (SEM). Finally, the powder was studied for flow ability evaluation followed by capsulation and in-vitro dissolution study along with various capsule characteristic evaluation.

\section{MATERIALS AND METHODS}

\section{Chemicals and Reagents}

GLC as white crystalline powder with ' $\mathrm{d}_{50}$ ' value as $40 \mu$ (particle size) was generously donated by IKOP Sdn Bhd (Malaysia). Soluplus ${ }^{\circledR}$ was obtained as gift sample from BASF SE (Germany) in yellowish white free flowing powder form. Bovine gelatin capsules (size 1) were donated by IKOP Sdn Bhd (Malaysia). Aerosil ${ }^{\circledR}$ R 972 was obtained as gift sample from Evonik Industries AG (Germany). Acetonitrile (HPLC grade) and methanol (analytical grade) were purchased from Merck KGaA (Germany).

\section{Miscibility Study between Drug and Polymer}

Excess amount of GLC and the solution of Soluplus ${ }^{\circledR}$ $(1-15 \% \mathrm{w} / \mathrm{v}$ in water) were sealed in small bottles and shaken at $37 \pm 0.5^{\circ} \mathrm{C}$ for $24 \mathrm{~h}$ at $500 \mathrm{rpm}$ using incubator shaker (New Brunswick Innova 4000, Hauppauge, NY). The samples were filtered through a $0.45 \mu \mathrm{m}$ syringe filter and GLC concentration were determined spectrophotometrically at $227 \mathrm{~nm}$ using an UV-visible spectrophotometer (Shimadzu 1800, Tokyo, Japan). All the measurements were carried out in triplicates. The Gibbs equation was used to calculate the free energy transfer $\left(\Delta G^{0}\right)$ of GLC from pure water to the aqueous polymeric solution as followed:

$$
\Delta \mathrm{G}_{\mathrm{t}}^{0}=-2.303 \mathrm{RT} \log \left(\mathrm{S}_{0} / \mathrm{S}_{\mathrm{S}}\right)
$$

Where, $\mathrm{S}_{0} / \mathrm{S}_{\mathrm{s}}$ is the ratio of molar solubility of GLC in aqueous solutions of carrier to that of the same medium without carrier. $R$ and $T$ are the universal gas constant and temperature in Kelvin respectively.

One to one complex apparent stability constant (Ka) was determined as follows:

$$
\mathrm{Ka}=\text { Slope / Intercept (1-Slope) }
$$

Where, slope and intercept were obtained from the graph of mean GLC concentration in $\mu \mathrm{g} / \mathrm{mL}$ vs respective Soluplus ${ }^{\circledR}$ concentration ( $\left.\% \mathrm{w} / \mathrm{v}\right)$.

\section{Preparation of Solid Dispersion}

Solid dispersion was prepared by conventional solvent evaporation method. Required amount of GLC was dissolved in lowest possible quantity of ethanol and Soluplus ${ }^{\circledR}$ was dispersed in the solution. The mixture was then subjected to dry using a rotary vacuum evaporator (BUCHI R 210, Switzerland). The almost dried residue was collected from the flask and kept in desiccator containing calcium chloride to remove residual ethanol. The solid formulation was then pulverized, passed through sieve (mesh no: 70) sieve and stored in air-tight bag for further studies. GLC: Soluplus ${ }^{\circledR}$ used to prepare solid dispersion were 1:1, 1:3, 1:5 and 1:8 w/w.

\section{Saturation Solubility Study}

Solid dispersed GLC powder and physical mixture (prepared in same ratio as per the solid dispersed powder) 
containing equivalent amount of excess GLC were added to $10 \mathrm{~mL}$ of distilled water in small vials followed by sealing and shaking at $37 \pm 0.5^{\circ} \mathrm{C}$ for $48 \mathrm{~h}$ at $500 \mathrm{rpm}$ using an incubator shaker. The samples taken were analyzed by UV spectrophotometry at $227 \mathrm{~nm}$ after subsequent dilution. The drug solubility data was calculated using a pre-constructed linearity curve. From aqueous solubility data GLC: Soluplus ${ }^{\circledR}$ ratio was finalized as solid dispersion composition for further characterization and capsulation. That finalized solid dispersion was abbreviated as $\mathrm{SD}_{\mathrm{GLC}}$ in further discussion.

\section{Solid State Characterization of GLC-Soluplus ${ }^{\circledR}$ Solid Dispersion}

\section{Differential Scanning Calorimetry (DSC)}

Thermograms of pure GLC, Soluplus ${ }^{\circledR}$, physical mixture of GLC: Soluplus ${ }^{\circledR}$ (referred as $\mathrm{PM}_{\mathrm{GLC}}$ hereafter) and $\mathrm{SD}_{\text {GLC }}$ were derived by a Differential Scanning Calorimeter (1-STARe, Mettler Toledo, Columbus, OH). The sample (8-10 $\mathrm{mg}$ ) was enclosed in an aluminium crucible and exposed to a thermal range of $50-250^{\circ} \mathrm{C}\left(10^{\circ} \mathrm{C} / \mathrm{min}\right)$ under a constant nitrogen flow $(10-20 \mathrm{~mL} / \mathrm{min})$. A closed aluminum crucible without sample was used as the blank.

\section{Attenuated Total Reflectance Spectroscopy (ATR-IR)}

ATR-IR was studied to determine compatibility and possible interactions of GLC with Soluplus ${ }^{\circledR}$ in physical mixture and solid dispersed powder. Pure GLC, pure Soluplus ${ }^{\circledR}, \mathrm{PM}_{\mathrm{GLC}}$ and $\mathrm{SD}_{\mathrm{GLC}}$ sample $(50-70 \mathrm{mg}$ ) were firmly clamped against the ATR diamond crystal with force $<90$ units and scanned over an IR range of 4000$400 \mathrm{~cm}^{-1}$ with accumulations 15 scans at resolution $2 \mathrm{~cm}^{-1}$ by an IR spectrometer (Parkin Elmer). The functional groups denoted by IR spectrum were compared between all samples and analyzed afterward.

\section{Scanning Electron Microscopy (SEM)}

A scanning electron microscope (Evo 50, Carl Zeiss, Carl Zeiss Microscopy, Jena, Germany) was employed to study the morphology of pure GLC, PM $\mathrm{GLC}_{\mathrm{C}}$ and $\mathrm{SD}_{\mathrm{GLC}}$. A small amount of sample was sprinkled onto the sample holder with a double sided carbon tape sticking to it. The sample was then coated with gold by a table top sputter coater (Leica EM SCD005, Leica Microsystems (SEA) Pte. Ltd., Singapore) in order to make a thin conductive film. The SEM micrographs, captured by the inbuilt software were then compared with visual observation.

\section{Powder X-ray Diffractometry (PXRD)}

PXRD study was carried out to determine the crystallinity of the solid dispersed powder using an x-ray diffractom- eter (Rigaku Ultima IV, Japan). The sample powder was placed on the PXRD sample holder and scanned from $0^{\circ}$ to $70^{\circ}$ with a rate of $5^{\circ} / \mathrm{min}$ where $\mathrm{Cu}-\mathrm{K} \alpha$ radiation was $30 \mathrm{kV}$ and $15 \mathrm{~mA}$. Diffraction angles $(2 \theta)$ were recorded along with intensity and compared between pure GLC, $\mathrm{PM}_{\mathrm{GLC}}$ and $\mathrm{SD}_{\mathrm{GLC}}$.

\section{Pre-Capsulation Studies: Moisture Content and Flow Property}

The $\mathrm{SD}_{\mathrm{GLC}}$ and $\mathrm{PM}_{\mathrm{GLC}}$ powders were tested for moisture content by a Halogen Moisture Analyzer (METTLER TOLEDO, Canada) before filling into gelatin capsule.

Before flow property measurement $0.5 \mathrm{wt} \%$ of Aerosil ${ }^{\circledR}$ was mixed properly with both $\mathrm{PM}_{\mathrm{GLC}}$ and $\mathrm{SD}_{\mathrm{GLC}}$ powder. Aerosil ${ }^{\circledR}$ is widely used as a glidant or flow- modifier in formulation of tablet or capsule. Flow property was analyzed by determining the flow indicators such as Carr index (CI) and Hausner ratio (HR). Bulk density $\left(\varrho_{\mathrm{BD}}\right)$ and tapped density $\left(\varrho_{\mathrm{TD}}\right)$ was measured by a graduated measuring cylinder and tap densitometer as per the method described by Ruzaidi et al. ${ }^{14}$ Pre-weighed samples were poured into the measuring cylinder. Poured bulk volume was measured after manual tapping of the cylinder on a flat surface. Tapped volume was measured after tapping the cylinder by tap density tester (Copley scientific, JV1000) for 500, 750 and 1250 taps. Two factor ANOVA was applied to evaluate and compare the significance of CI values. CI and HR were calculated using the following equations:

$$
\begin{gathered}
\mathrm{CI}=\frac{\rho_{\mathrm{TD}}-\rho_{\mathrm{BD}}}{\rho_{\mathrm{TD}}} \\
\mathrm{HR}=\frac{\rho_{\mathrm{TD}}}{{ }_{\mathrm{BD}}}
\end{gathered}
$$

\section{Capsulation of the Powder}

$\mathrm{SD}_{\mathrm{GLC}}$ and $\mathrm{PM}_{\mathrm{GLC}}$ powders (pre-mixed with Aersoil $($ ) equivalent to $20 \mathrm{mg}$ of GLC was filled into bovine gelatin capsule of size 1 using a manual capsule filling machine. Theoretically there should be $189 \mathrm{mg}$ of powder in each capsule which includes solid dispersed or physically mixed GLC with Soluplus ${ }^{\circledR}$ and Aerosil ${ }^{\circledR}$.

\section{Physicochemical Evaluation of Filled Capsule Weight Variation, Assay and Disintegration Time}

Both types of the powder filled capsules $\left(\mathrm{PM}_{\mathrm{GLC}}\right.$ and $\mathrm{SD}_{\mathrm{GLC}}$ ) were subsequently characterized for weight variation by weighing randomly 20 capsules using an electrical balance. The average weight was calculated followed by calculation of relative standard deviation (\% RSD) using the average weight. 
The assay was done to quantify the GLC content in capsule. GLC powder equivalent to $20 \mathrm{mg}$ was taken from the powder mix collected from randomly selected and pre-weighed 20 capsules and dissolved in $20 \mathrm{ml}$ of methanol using a magnetic stirrer. The sample was the measured for the absorbance at $227 \mathrm{~nm}$ using a UV-Vis spectrophotometer after filtering and required dilution. The percentage drug content was calculated using a linearity curve constructed covering the detectable range. Disintegration tests were performed by a six station USP disintegration apparatus (Electro lab ED-2L, India) using $0.1(\mathrm{~N}) \mathrm{HCl}$ with temperature maintenance at $37 \pm 2{ }^{\circ} \mathrm{C}$. The time taken by the capsules to disintegrate completely into the medium were recorded using a stopwatch.

\section{In-vitro Dissolution}

In-vitro dissolution study was done by a USP type I basket type apparatus using two different medium such as $0.1 \mathrm{~N}$ $\mathrm{HCl}(\mathrm{pH}$ 1.2) and phosphate buffer $\mathrm{pH} 7.4$ where the medium volume was $900 \mathrm{ml}$ at $37 \pm 2^{\circ} \mathrm{C}$. The samples were taken at 15, 30, 60 and 120 min and analyzed by high performance liquid chromatographic (HPLC) system coupled to UV detector after filtering and required dilution. The HPLC parameters can be briefly summarized as; column: Agilent Zorbax C18 (250×4.6 mm diameter, $5 \mu$ pore size), elution: isocratic, mobile phase: acetonitrile: water (70:30) v/v, detection wavelength: $227 \mathrm{~nm}$, chromatographic run time: 7 min, GLC retention time: 4.324 min. The cumulative percent drug release was calculated from the area response derived from the samples and reference standard of GLC and plotted against time in minutes. Both type of powder filled capsules such as $\mathrm{SD}_{\mathrm{GLC}}$ and $\mathrm{PM}_{\mathrm{GLC}}$ were used to compare the in-vitro dissolution study. Therefore, similarity factor $\left(\mathrm{f}_{2}\right)$ have been calculated to compare the dissolution profile of $\mathrm{SD}_{\mathrm{GLC}}$ and $\mathrm{PM}_{\mathrm{GLC}}$ capsules as well as to compare the dissolution of both capsules with respect to different $\mathrm{pH}$. The equation used to calculate $\mathrm{f}_{2}$ is given below. ${ }^{15}$

$$
\mathrm{f}_{2}=50 *\left[\left\{1+£(\mathrm{RT}-\mathrm{Tt})^{2} * 1 / \mathrm{n}\right\}^{-0.5} * 100\right]
$$

Where, $R t$ is GLC dissolution from $\mathrm{SD}_{\mathrm{GLC}}$ capsule, $T t$ is GLC dissolution from $\mathrm{PM}_{\mathrm{GLC}}$ capsule and $n$ is number of sampling points $(n=4)$ in the present research.

\section{RESULTS}

\section{Miscibility Study between Drug and Polymer}

The results of miscibility study using Gibbs' equation were expressed in Table 1 . The miscibility of GLC with Soluplus ${ }^{\circledR}$ showed a linear relationship with $\mathrm{R}^{2}$ (correlation co-efficient $)=0.9896$. With increasing concen- tration of Soluplus ${ }^{\circledR}$ the molar solubility of GLC was increased up to 23.10 at $10 \% \mathrm{w} / \mathrm{w}$ Soluplus ${ }^{\circledR}$ concentration. From Gibbs' energy calculation all the $\Delta \mathrm{G}^{0}$ values were shown negative. The negative values indicated spontaneous solubilization of drug with the polymer. ${ }^{16}$ The Ka value determines the affinity of the drug towards polymer. The higher the Ka value, the better the affinity. GLC showed positive and quite high Ka value indicating good affinity of the drug with Soluplus ${ }^{\circledR}$.

\section{Aqueous Solubility Study and Determination of Final GLC-Soluplus ${ }^{\circledR}$ Ratio}

Aqueous solubility data of different solid dispersed materials and physical mixtures were described by Figure 1. It was observed that aqueous solubility of GLC increased in presence of Soluplus ${ }^{\circledR}$ irrespective of physical mixture or solid dispersed powder. However, the solid dispersed materials showed better improvement of GLC solubility than physical mixture at all drug: carrier ratios. With increased ratio of Soluplus ${ }^{\circledR}$, GLC solubility was increased from $1.32 \mathrm{mg} / \mathrm{ml}$ (GLC: Soluplus ${ }^{\circledR} ; 1: 3$ ) to $2.36 \mathrm{mg} / \mathrm{ml}$ (GLC: Soluplus $\left.{ }^{\circledR} ; 1: 8\right)$. Despite the fact that the higher the polymer the better the solubility, we restricted the carrier amount to $8 \mathrm{gm}$ with respect to $1 \mathrm{gm}$ of GLC because higher carrier amount will have negative impact of the feasibility of final dosage form using solid dispersed powder. This GLC: Soluplus ${ }^{\circledR}$ $(1: 8 \mathrm{w} / \mathrm{w})$ ratio was used as final composition for solid dispersion (termed as $\mathrm{SD}_{\text {GLC }}$ hereafter) and used for further solid state characterization as capsulation.

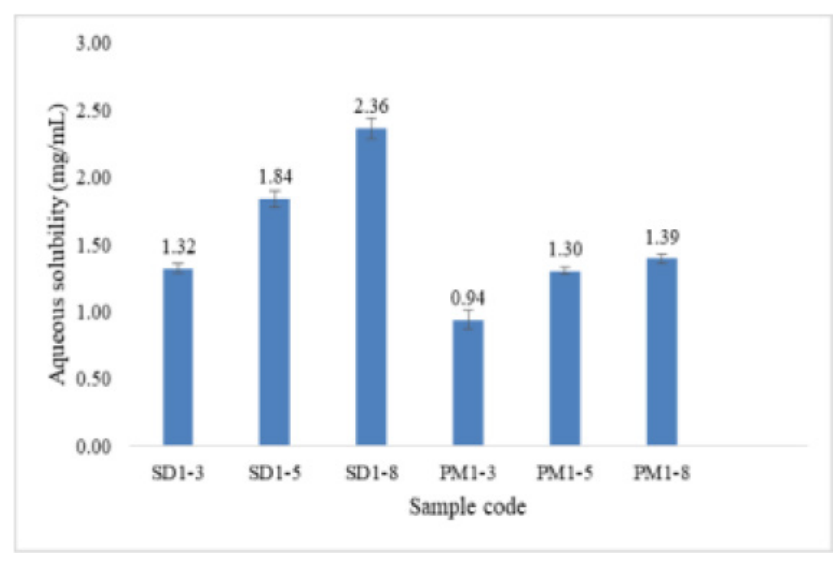

Figure 1: Aqueous solubility of solid dispersed GLC powder and respective physical mixtures SD1-3: Solid dispersed GLC powder with GLC: Soluplus $₫(1: 3 \mathrm{w} / \mathrm{w})$, SD1-5: Solid dispersed GLC powder with GLC: Soluplus ${ }^{\circledR}(1: 5 \mathrm{w} / \mathrm{w})$, SD1-8: Solid dispersed GLC powder with GLC: Soluplus ${ }^{\circledR}(1: 8 \mathrm{w} / \mathrm{w})$, PM1-3: Physical mixture of GLC: Soluplus $₫$ (1:3 w/w), PM1-5: Physical mixture of GLC: Soluplus ${ }^{\circledR}(1: 5 \mathrm{w} / \mathrm{w}), \mathrm{PM} 1-8$ : Physical mixture of GLC: Soluplus $₫(1: 8 \mathrm{w} / \mathrm{w})$. 


\section{Solid State Characterization}

\section{DSC Analysis}

The thermograms obtained from DSC analysis was presented by Figure 2. Pure GLC showed a sharp endothermic peak at $171^{\circ} \mathrm{C}$ clearly indicating its crystalline

\begin{tabular}{|c|c|}
\hline Table 1: Parameters describing miscibility study \\
\hline $\begin{array}{c}\text { Concentration of Soluplus }{ }^{\circledR} \\
\% \mathrm{w} / \mathrm{w}\end{array}$ & $\Delta \mathrm{G}^{0}{ }_{\mathrm{t}}$ \\
\hline 1 & -24.39 \\
\hline 2 & -25.75 \\
\hline 5 & -27.98 \\
\hline 10 & -29.8 \\
\hline 15 & -30.36 \\
\hline Slope & 0.544 \\
\hline Intercept & 0.238 \\
\hline $\mathrm{K}_{\mathrm{a}}$ & 5.017 \\
\hline
\end{tabular}

Ka: Apparent stability constant

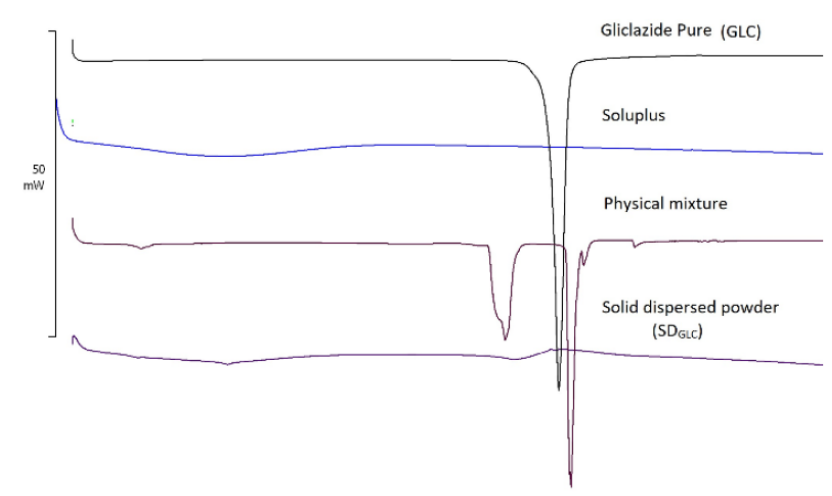

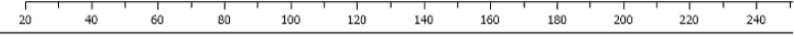

Figure 2: Combined DSC thermogram of Soluplus ${ }^{\circledR}$, GLC and SDGLC.

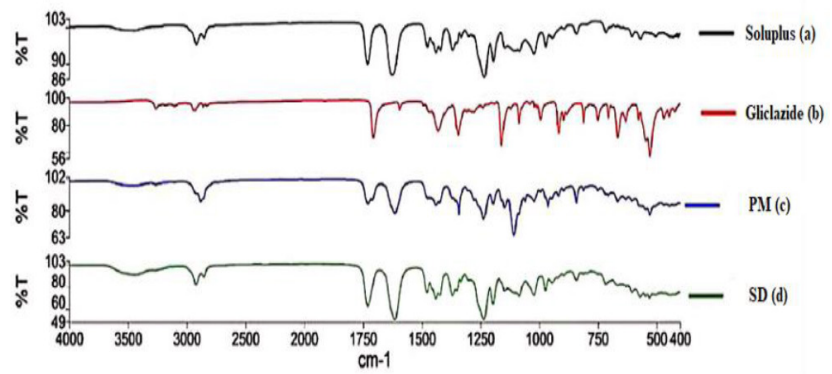

Figure 3: ATR-IR spectra of Soluplus ${ }^{\circledR}(a)$, GLC (b), PMGLC(c) and SDGLC (d).

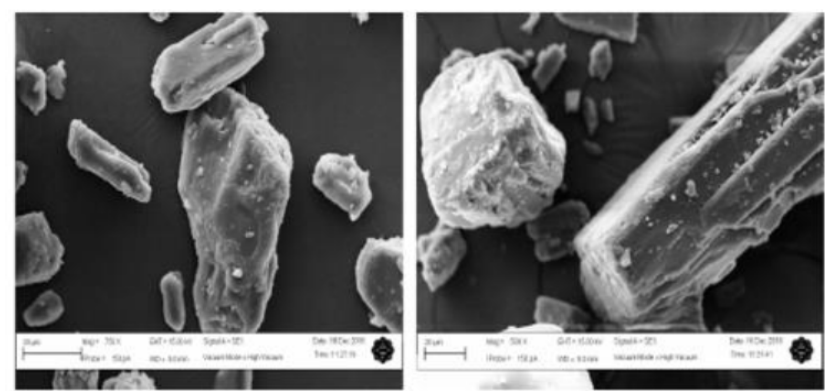

a

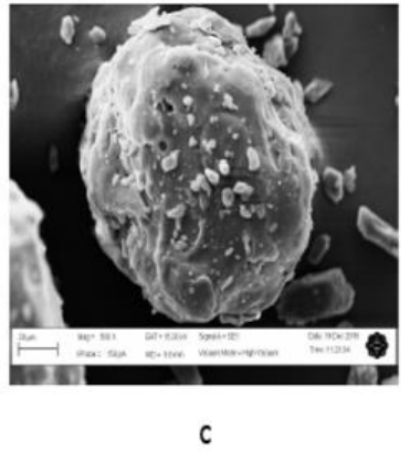

b

Figure 4: SEM micrograph of pure GLC (a), PMGLC (b) and SDGLC (c).

nature. Soluplus ${ }^{\circledR}$ showed two broad endothermic band at 74.22 and $316^{\circ} \mathrm{C} . \mathrm{PM}_{\mathrm{GLC}}$ showed presence of GLC peak with a little forward shift. $\mathrm{SD}_{\text {GLC }}$ thermogram showed a broad and small endotherm at $165^{\circ} \mathrm{C}$.

\section{ATR-IR Spectroscopy}

The IR spectrum for GLC and Soluplus ${ }^{\circledR}$ was compared with the spectrum of $\mathrm{PM}_{\mathrm{GLC}}$ and $\mathrm{SD}_{\mathrm{GLC}}$ with respect to the key functional groups. The combined spectra for all samples are represented by Figure 3. IR spectra of GLC is characterized by distinct IR peaks at $1707 \mathrm{~cm}^{-1}$ (absorption of $\mathrm{C}=\mathrm{O}$ group), 1162, and $1345 \mathrm{~cm}^{-1}$ (stretching vibration of $\mathrm{S}=\mathrm{O}$ of sulphonyl urea group). ${ }^{17}$ In $\mathrm{PM}_{\mathrm{GLC}}$ and $\mathrm{SD}_{\mathrm{GLC}}$ the peaks at $1707 \mathrm{~cm}^{-1}$ was shifted towards little higher frequency at $1725 \mathrm{~cm}^{-1}$. The peak at $3269 \mathrm{~cm}^{-1}$ due to $\mathrm{NH}$ group belonging to pure GLC is shifted to $3462 \mathrm{~cm}^{-1}$ in $\mathrm{PM}_{\mathrm{GLC}}$ which is further absent in $\mathrm{SD}_{\mathrm{GLC}}$. Soluplus ${ }^{\circledR}$ spectra is identified by characteristic peaks at $3452 \mathrm{~cm}^{-1}$ (O-H stretching), $2927.44 \mathrm{~cm}^{-1}$ (aromatic C-H stretching), 1732 and $1635 \mathrm{~cm}^{-1}(\mathrm{C}=\mathrm{O}$ stretching). All these peaks of Soluplus ${ }^{\circledR}$ are present in $\mathrm{PM}_{\mathrm{GLC}}$ however there are little shift of $\mathrm{C}=\mathrm{O}$ stretching $\left(1635 \mathrm{~cm}^{-1}\right)$ to lower wavelength $\left(1615 \mathrm{~cm}^{-1}\right)$ in $\mathrm{SD}_{\text {GLC. }}$ The presence of major characteristic peaks of GLC and Soluplus ${ }^{\circledR}$ in PM $_{\text {GLC }}$ can be considered as evidence of no potential incompatibilities between the drug and carrier. The peak shifting from GLC to $\mathrm{SD}_{\mathrm{GLC}}$ is attributed to the desirable physical interaction between drug and carrier. 


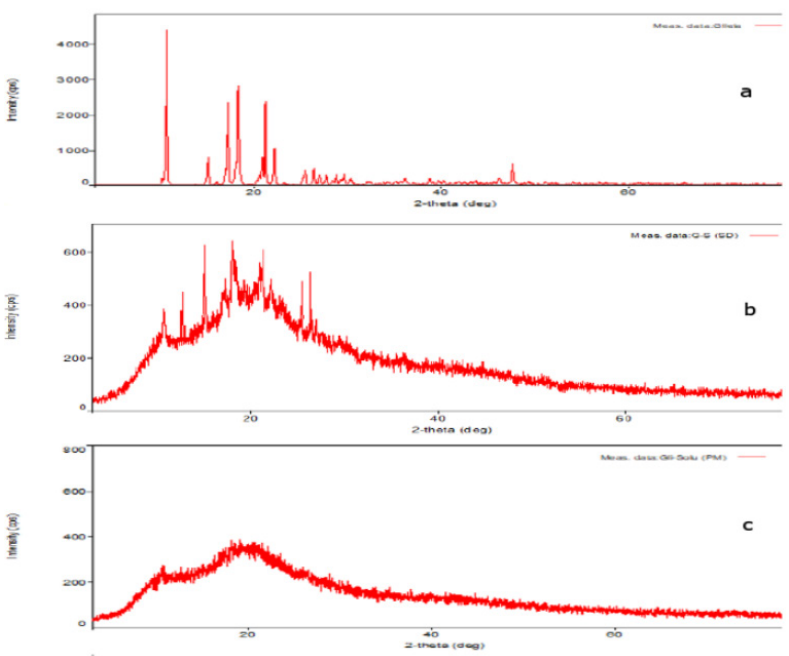

Figure 5: X-ray diffractogram of pure GLC (a), PMGLC (b) and SDGLC (c).

\section{Scanning Electron Microscopy (SEM)}

The photomicrographs obtained from SEM study were presented by Figure 4. Pure GLC was shown to be irregular shaped crystal in the photomicrograph of pure GLC. In PM ${ }_{G L C}$ drug crystals were found separately

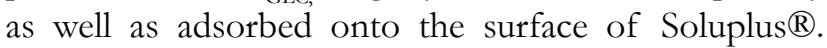
However, in $\mathrm{SD}_{\mathrm{GLC}}$ the drug crystals were shown to be adsorbed onto the surface of Soluplus $\AA$ in fine particle size. Although not very clear but some GLC crystal were still visible in $\mathrm{SD}_{\text {GLC }}$. The porous surface of solid dispersed granules was also observed.

\section{Crystallinity Analysis (PXRD)}

PXRD has been established as a powerful tool to determine the crystallinity of powder material. The results of XRD analysis were represented by the derived diffractogram (Figure 5). The crystalline nature of pure GLC

\begin{tabular}{|c|c|c|c|c|}
\hline \multicolumn{5}{|c|}{ Table 2: Pre-capsulation flow property and moisture content determination of powders } \\
\hline Capsule type & $\begin{array}{c}\mathrm{Cl} \pm \\
\mathrm{SD}(\mathrm{n}=3)\end{array}$ & $\begin{array}{c}\text { Flow property classification } \\
\text { (USP) }\end{array}$ & $\begin{array}{c}\mathrm{HR} \pm \mathrm{SD} \\
(\mathrm{n}=3)\end{array}$ & Flow property classification (USP) \\
\hline $\mathrm{PM}_{\mathrm{GLC}}$ & $17.67 \pm 1.28$ & $16-20$; Flow property: Fair & $1.21 \pm 0.019$ & $1.19-1.25$; Flow property: Fair \\
\hline $\mathrm{SD}_{\mathrm{GLC}}$ & $11.90 \pm 1.81$ & $10-15 ;$ Flow property: Good & $1.14 \pm 0.023$ & $1.12-1.18$; Flow property: Good \\
\hline
\end{tabular}

$\mathrm{Cl}$ : Carr index, HR: Hausner ratio, $\mathrm{PM}_{\mathrm{GLC}}$ : Physical mixture of GLC:Soluplus ${ }^{\circledR}(1: 8) \mathrm{w} / \mathrm{w}, \mathrm{SD}_{\mathrm{GLC}}$ : Solid dispersion of GLC:Soluplus ${ }^{\circledR}(1: 8)$ w/w

\begin{tabular}{|c|c|c|c|c|c|c|}
\hline \multirow[t]{2}{*}{$\begin{array}{l}\text { Type of } \\
\text { capsule }\end{array}$} & \multicolumn{2}{|c|}{ Weight variation } & \multirow{2}{*}{$\begin{array}{c}\text { Assay } \\
\text { Mean (\%) }\end{array}$} & \multirow[b]{2}{*}{$S D(n=3)$} & \multicolumn{2}{|c|}{ Disintegration time } \\
\hline & Mean weight(mg) & $\%$ RSD & & & Mean (min) & $\operatorname{SD}(n=6)$ \\
\hline $\mathrm{PM}_{\mathrm{GLC}}$ & 187.00 & 0.63 & 98.99 & 4.13 & 12.40 & 0.58 \\
\hline $\mathrm{SD}_{\mathrm{GLC}}$ & 192.93 & 1.23 & 97.52 & 5.04 & 14.80 & 1.03 \\
\hline
\end{tabular}

$(1: 8) w / w$

Table 4: Similarity factor $\left(f_{2}\right)$ values between different type of capsules and different type of medium

\begin{tabular}{|c|c|c|}
\hline \multicolumn{3}{|c|}{$f_{2}$ values } \\
\hline & $0.1(\mathrm{~N}) \mathrm{Hcl}$ & $\begin{array}{c}\text { Phosphate } \\
\text { buffer } \mathrm{pH} 7.4\end{array}$ \\
\hline $\begin{array}{l}\text { Between } \mathrm{SD}_{\mathrm{GLC}} \\
\text { and } \mathrm{PM}_{\mathrm{GLC}}\end{array}$ & 36.39 & 37.35 \\
\hline & $\mathrm{SD}_{\mathrm{GLC}}$ & $\mathrm{PM}_{\mathrm{GLC}}$ \\
\hline $\begin{array}{c}\text { Between } 0.1(\mathrm{~N}) \\
\mathrm{Hcl} \text { and phosphate } \\
\text { buffer } \mathrm{pH} 7.4\end{array}$ & 74.47 & 67.28 \\
\hline
\end{tabular}




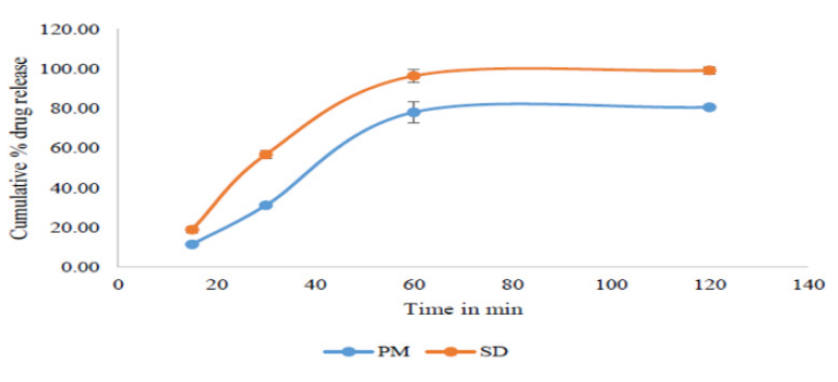

(a)

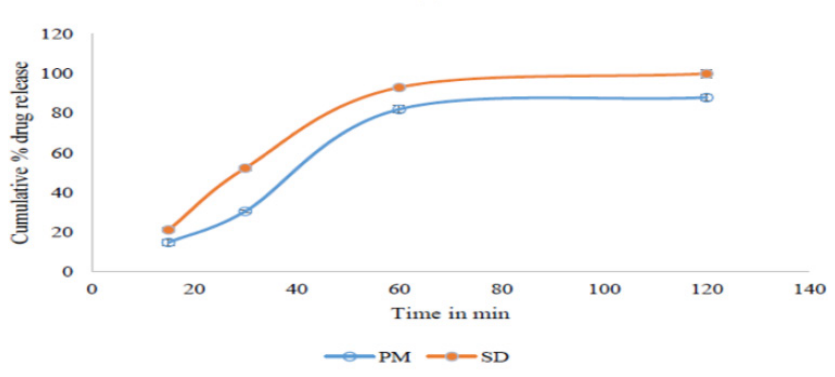

(b)

Figure 6: In vitro dissolution plot (Time in min vs Cumulative percent release) of PMGLC and SDGLC capsules.

(a) Dissolution in 0.1(N) Hcl, (b) Dissolution in phosphate buffer pH 7.4 .

was characterized by sharp peaks at $2 \theta$ of $10.69^{\circ}, 15.08^{\circ}$, $17.23^{\circ}, 18.04^{\circ}, 22.21^{\circ}, 25.47^{\circ}$. The highest height of the peak was $3057 \mathrm{cps}$ at $2 \theta$ of $10.69^{\circ}$. The results were in close agreement with previously published research. ${ }^{18}$ In the $\mathrm{PM}_{\mathrm{GLC}}$, peaks of pure GLC at various $2 \theta$ angle were observed but with reduced intensity, which indicated that the crystallinity of GLC was maintained in the physical mixture. Reduction of peak intensity might attribute to the slight amorphous nature of GLC generated during physical mixing of GLC and Soluplus ${ }^{\circledR}$ to prepare sample for XRD. In $\mathrm{SD}_{\mathrm{GLC}}$ no sharp peak of pure GLC was visible indicating complete conversion of crystalline drug to amorphous form. This result is in-line with the findings of DSC analysis.

\section{Moisture Content and Flow Property Analysis}

Excess moisture present in the powder may affect the flow ability as well as stability of the solid dispersion. All the powders showed moisture content below 1.3\%. $\mathrm{CI}$ and HR are two established flow indicators as per the compendia. ${ }^{19}$ The resulted CI and HR values (Table 2) showed that $\mathrm{SD}_{\text {GLC }}$ powder possessed better flow property than physical mixture. The difference in the two flow indicator values were statistically significant. This can be due to size uniformity derived after sieving. Although the flow ability of $\mathrm{SD}_{\mathrm{GLC}}$ powder was not "excellent" as per the flow property table ${ }^{19}$ but the values of CI (11.90 \pm 1.81$)$ and HR (1.14 \pm 0.023$)$ reached near the "excellent" region.

\section{Physicochemical Analysis of Filled Capsule}

Results of weight variation, disintegration and assay tests were presented in Table 3. The experimental evaluation showed low $\%$ RSD of weight between 20 capsules $\left(\mathrm{SD}_{\mathrm{GLC}}: 0.63, \mathrm{PM}_{\mathrm{GLC}}: 1.22\right)$. The weight range of all weighed capsule was 185 to $189 \mathrm{mg}$ and 190 to $193 \mathrm{mg}$ for $\mathrm{SD}_{\mathrm{GLC}}$ and $\mathrm{PM}_{\mathrm{GLC}}$ powder filled capsule respectively and no capsule was beyond the $\pm 5 \%$ level of their average weight. Therefore, the weight variation can be considered as acceptable for both type of capsules. ${ }^{20}$

The results of disintegration test showed (Table 3) that the time of complete disintegration for both types of capsule were less than $14.8 \mathrm{~min}$. If the capsule took longer time to disintegrate then its bioavailability would also be affected. Solubility of the drug and excipient is major contributing factor of proper disintegration. ${ }^{21}$ In order to facilitate capsule disintegration, various disintegrants can be used such as corn starch, sodium starch glycolate etc. However, in this research favourable disintegration has been achieved without any disintegrant. The assay performed with filled capsules showed acceptable results for both type of capsule (Table 3). Mean assay of 3 set of analysis were 97.52 and $98.99 \%$ (with respect to $20 \mathrm{mg}$ of GLC) which is within the general acceptable limit which is $95-105 \%$ of the label claim. This result ensures that GLC was loaded as solid dispersed powder properly.

In-vitro dissolution study was carried out in two different mediums; $0.1(\mathrm{~N}) \mathrm{HCl}(\mathrm{pH} 1.2)$ and phosphate buffer $(\mathrm{pH}$ 7.4). GLC was reported in literatures to possess $\mathrm{pH}$ dependant solubility in aqueous medium. In $\mathrm{pH} 1.2$ it is more soluble than $\mathrm{pH}$ than $\mathrm{pH}$ 4.5-5. Then with increasing $\mathrm{pH}$ from 6 to higher, the solubility of GLC is increased. ${ }^{22}$ In this research, formulation of GLC was either mixed or solid dispersed in Soluplus ${ }^{\circledR}$ which is claimed to bear $\mathrm{pH}$ independent solubility. A low $\mathrm{pH}$ (1.2) and a high $\mathrm{pH}$ (7.4) dissolution mediums were used to determine whether solubility improvement reflects into improved dissolution in both medium or not. The results of the in-vitro dissolution study were presented by Figure 6 .

The $f_{2}$ has been calculated (Table 4) to compare the dissolution profile of $\mathrm{SD}_{\mathrm{GLC}}$ and $\mathrm{PM}_{\mathrm{GLC}}$ with respect to two different $\mathrm{pH}$. In both $\mathrm{pH}, \mathrm{SD}_{\mathrm{GLC}}$ resulted better dissolution profile compared to $\mathrm{PM}_{\mathrm{GLC}}$ capsule. In case of $\mathrm{SD}_{\text {GLC }}$ capsule more than $92 \%$ of drug was dissolved in both mediums whereas only more than $78 \%$ drug has been released from $\mathrm{PM}_{\mathrm{GLC}}$. Considering initial time points also $\mathrm{SD}_{\mathrm{GLC}}$ capsule performed better with $50 \%$ drug release within 30 min compared to $\mathrm{PM}_{\mathrm{GLC}}$ capsule with $50 \%$ drug release after $40 \mathrm{~min}$. The $\mathrm{f}_{2}$ value was 
used to compare dissolution profile between two different formulations. Two formulations were considered similar if $f_{2}$ value lies within $50-100 .{ }^{15}$ In our research $f_{2}$ value between $\mathrm{SD}_{\mathrm{GLC}}$ and $\mathrm{PM}_{\mathrm{GLC}}$ capsules are 36.29 $(0.1$ (N) $\mathrm{HCl}$ ) and 37.35 (phosphate buffer $\mathrm{pH}$ 7.4) which indicated the dissimilarity between the two in-vitro drug dissolution profile.

Comparison of in-vitro dissolution profile between two different dissolution mediums $(\mathrm{pH} 1.2$ and $\mathrm{pH}$ 7.4) resulted no significance difference in cumulative percent release as well as $\mathrm{f}_{2}$ value. Regarding $\mathrm{SD}_{\mathrm{GLC}}$ capsule within $1 \mathrm{~h}$ in-vitro dissolution was $96.52 \%$ in phosphate buffer $\mathrm{pH} 7.4$ whereas in $0.1(\mathrm{~N}) \mathrm{HCl}$ it was $92.99 \%$. Same applied to $\mathrm{PM}_{\mathrm{GLC}}$ capsule as well. It showed dissolution of $78.17 \%$ in 0.1 (N) $\mathrm{HCl}$ and $81.95 \%$ in phosphate buffer $\mathrm{pH} 7.4$ indicating almost same rate and extent of dissolution. The $\mathrm{f}_{2}$ values (Table 4) derived from the dissolution profile of both type of capsules in two different mediums are above 50 ( $\mathrm{SD}_{\mathrm{GLC}}$ : 74.47, $\mathrm{PM}_{\mathrm{GLC}}$ : 67.28). This indicated the similarity between the dissolution profiles in two different mediums with respect to same type of capsule.

\section{DISCUSSION}

Increase in drug-polymer miscibility with increasing polymer concentration was also evidenced by the previous work. ${ }^{5}$ Application of Gibbs equation mathematically supported the observation. Soluplus ${ }^{\circledR}$ has a large number of -OH groups making it hydrophilic polymeric solubilizer for poor soluble drug. The formation of micelle is one of the responsible factors behind increased GLC solubility with increase in Soluplus ${ }^{\circledR}$ concentration.

If results of all solid-state characterization studies were summarized, a clear understanding of GLC and Soluplus ${ }^{\circledR}$ interaction can be developed. In DSC thermogram of $\mathrm{SD}_{\text {GLC }}$, sharp melting peak of GLC was absent. This feature was attributed to strong interaction between drug and polymer that inhibited crystalline behavior of GLC suggesting that the drug was present in amorphous form. ${ }^{6}$ This was further supported by ATR-IR specta. The absence of $\mathrm{NH}$ peak of pure GLC in $\mathrm{SD}_{\mathrm{GLC}}$ indicated possible interaction between -NH group of GLC and ketone group of Soluplus ${ }^{\circledR}$ to form amide bond. ${ }^{8}$ Additionally the asymmetric stretching vibration band of sulphonyl group in GLC at $1345 \mathrm{~cm}^{-1}$ was shifted to higher wavelength at $1371 \mathrm{~cm}^{-1}$ in $\mathrm{SD}_{\mathrm{GLC}}$ that potentially indicated the formation of $\mathrm{H}$ bond with Soluplus ${ }^{\circledR} .{ }^{17}$ In SEM micrograph, absence of distinct GLC crystals in $\mathrm{SD}_{\mathrm{GLC}}$ indicated amorphization of drug. The porous surface seen in SEM micrograph with high hydrophilicity of the career has caused faster drug dissolution. ${ }^{23}$ In
PXRD peaks with decreased intensity, featureless scattering peaks or fused peaks with no/less sharp peaks were the indications of reduction or absence of crystallinity. Presence of no sharp peaks of pure GLC in SD $_{\text {GLC }}$ indicated the amorphization of GLC in Soluplus ${ }^{\circledR}$ solid dispersion. GLC has a high melting point $\left(171^{\circ} \mathrm{C}\right)$ which is indicative of strong crystal energy and that is one of the factor behind its poor aqueous solubility. Therefore, any approach to break the crystal structure and to reduce the crystal energy could be beneficial towards improvement of drug solubility. Solid-state dispersion has the ability to rupture the crystalline nature of the drug by dispersing it into water soluble carrier molecules replacing the drug molecule in the crystal lattice. This resulted in a complete or partial loss of crystallinity and thereby significantly improved aqueous solubility of the drug. Soluplus ${ }^{\circledR}$ as a water-soluble polymer has been identified to maintain amorphous nature of the drug by inhibiting or retarding crystallization. Therefore the formulation of amorphous solid dispersions with it can increase drug dissolution rate and solubility. ${ }^{24-25}$

The moisture content was little higher in $\mathrm{SD}_{\text {GLC }}$ powder then PM $_{\text {GLC }}$ powder which was normal due to higher exposure to atmosphere than physical mixture. However, the present moisture did not affect the flow ability of the powder. Although the flow indicators studied in this research (CI and HR) had showed excellent; flow ability but flow property is not an intrinsic property of powder mass. It can be changed with type of measurements, handling and storage, moisture content and so on. ${ }^{15}$ Therefore, practically acceptable flow property must be determined during large scale powder handling. In in-vitro dissolution study, improved dissolution profile of $\mathrm{SD}_{\text {GLC }}$ capsule can be explained by improvement of solubility by $\mathrm{SD}_{\mathrm{GLC}}$ powder. Once the solid dispersed powder came in contact with the medium, it started to dissolve readily due to very fine or amorphous nature of drug which enhanced the surface area due to reduced crystallinity and enhanced the wettability due to the presence of hydrophilic solubilizer. ${ }^{8}$ Regarding similar dissolution profile in two different $\mathrm{pH}$ mediums, it can be explained that the presence of Soluplus ${ }^{\circledR}$ or the amorphization of GLC can improve drug solubility in both $\mathrm{pH}$ and that has been reflected in in-vitro dissolution.

\section{CONCLUSION}

The prepared GLC-Soluplus solid dispersed powder formulation with drug: polymer ratio $(1: 8 \mathrm{w} / \mathrm{w})$ has exhibited the improved solubility compared to pure GLC. Solid state characterization revealed conversion of crystalline drug to amorphous form along with 
certain degree of physical interaction. The improved solubility has reflected in the improved dissolution for solid dispersed GLC powder filled capsules. The flow property of solid dispersed powder was desirable for capsule filling. The solid dispersed GLC powder with Soluplus ${ }^{\circledR}$ can be used to formulate GLC capsules with improved dissolution in different $\mathrm{pH}$. However, the stability study with the capsules in proper packaging should be carried out before scale-up or further relevant action.

\section{ACKNOWLEDGEMENT}

The authors are thankful to IKOP SDN BHD, Malaysia for partial support of equipment and materials.

\section{CONFLICT OF INTEREST}

The authors declare no conflict of interest.

\section{ABBREVIATIONS}

GLC: Gliclazide; SD: Solid dispersion; CI: Carr index; HR: Hausner ratio; DSC: Differential scanning calorimetry; PXRD: Powder X-ray diffraction; SEM: Scanning electron microscopy; ATR-iR: Attenuated total reflectance infra-red.

\section{REFERENCES}

1. Serajuddin ATM. Salt formation to improve drug solubility. Adv Drug Deliv Rev. 2007;59(7):603-16.

2. Stella VJ, Nti-Addae KW. Prodrug strategies to overcome poor water solubility. Adv Drug Deliv Rev. 2007;59(7):677-94.

3. Khadka P, Ro J, Kim H, Kim I, Kim JT, Kim H, et al. Pharmaceutical particle technologies: An approach to improve drug solubility, dissolution and bioavailability. Asian J Pharm Sci. 2014;9(6):304-16.

4. Chatterjee B, HamedAS, Ahmed MDA, Mandal UK, Sengupta P. Controversies with self-emulsifying drug delivery system from pharmacokinetic point of view. Drug Deliv. 2016;23(9):3639-52.

5. Kyaw OM, Mandal UK, Chatterjee B. Polymeric behavior evaluation of PVP K30-poloxamer binary carrier for solid dispersed nisoldipine by experimental design. Pharm Dev Technol. 2017;22(1):2-12.

6. Baird JA, Taylor LS. Evaluation of amorphous solid dispersion properties using thermal analysis techniques. Adv Drug Deliv Rev. 2012;64(5):396-421.

7. Vo CLN, Park C, Lee BJ. Current trends and future perspectives of solid dispersions containing poorly water-soluble drugs. Eur J Pharm Biopharm. 2013;85(3):799-813.
8. Shamma RN, Basha M. Soluplus $®$ : A novel polymeric solubilizer for optimization of Carvedilol solid dispersions: Formulation design and effect of method of preparation. Powder Technol. 2013;237:406-14.

9. Lu J, Cuellar K, Hammer NI, Jo S, Gryczke A, Kolter K, et al. Solid-state characterization of Felodipine-Soluplus amorphous solid dispersions. Drug Dev Ind Pharm. 2016;42(3):485-96.

10. Fule R, Amin P. Development and evaluation of lafutidine solid dispersion via hot melt extrusion: Investigating drug-polymer miscibility with advanced characterisation. Asian J Pharm Sci. 2014;9(2):92-106.

11. Ha E, Baek I, Cho W, Hwang S, Kim M. Preparation and evaluation of solid dispersion of atorvastatin calcium with Soluplus ${ }^{\circledR}$ by spray drying technique. Chem Pharm Bull. 2014;62(6):545-51.

12. Biswal S, Sahoo J, Murthy PN, Giradkar RP, Avari JG. Enhancement of dissolution rate of gliclazide using solid dispersions with polyethylene glycol 6000. AAPS Pharm Sci Tech. 2008;9(2):563-70.

13. Maggi L, Canobbio A, Bruni G, Musitelli G, Conte U. Improvement of the dissolution behavior of gliclazide, a slightly soluble drug, using solid dispersions. J Drug Deliv Sci Technol. 2015;26:17-23.

14. Ruzaidi AF, Mandal UK, Chatterjee B. Glidant effect of hydrophobic and hydrophilic nanosilica on a cohesive powder: Comparison of different flow characterization techniques. Particuology. 2017;31:69-79.

15. VishnuPriya MB, Murthy TEGK. Development of Discriminative Dissolution Media for Marketed Gliclazide Modified-Release Tablets. Dissolut Technol. 2012;19(2):38-43.

16. Yadav PS, Kumar V, Singh UP, Bhat HR, Mazumder B. Physicochemical characterization and in vitro dissolution studies of solid dispersions of ketoprofen with PVP K30 and d-mannitol. Saudi Pharm J. 2013;21(1):77-84.

17. Lu Z, Yang Y, Covington RA, Bi Y, Dürig T, Fassihi R. Amorphous-based controlled-release gliclazide matrix system. AAPS Pharm Sci Tech. 2017;18(5):1699-09.

18. Yang $Y$, Zhao Z, Wang $Y$, Yang L, Liu D, Yang X, et al. A novel asymmetric membrane osmotic pump capsule with in situ formed delivery orifices for controlled release of gliclazide solid dispersion system. Int J Pharm. 2016;506(1-2):340-50.

19. United States Pharmacopeia-National Formulary (USP 29-NF 24) [Internet]. United States Pharmacopeial Convention. [cited 2017 Feb 9]. Available from: http://www.pharmacopeia.cn/v29240/usp29nf24s0_c1174.html.

20. Malakar J, Datta PK, Purakayastha SD, Dey S, Nayak AK. Floating capsules containing alginate-based beads of salbutamol sulfate: In vitro-in vivo evaluations. Int J Biol Macromol. 2014;64:181-9.

21. Hard gelatin capsules today - and tomorrow [Internet]. Capsugel Library; [updated 2002; cited 2017 Feb 9]. Available from: http://www.capsugel.com/ media/library/hard-gelatin-capsules-today-and-tomorrow.pdf.

22. Devarajan PV, Sonavane GS. Preparation and in vitro/in vivo evaluation of gliclazide loaded Eudragit nanoparticles as a sustained release carriers. Drug Dev Ind Pharm. 2007;33(2):101-11.

23. Sonali D, Tejal S, Vaishali T, Tejal G. Silymarin-solid dispersions: characterization and influence of preparation methods on dissolution. ACTA Pharm. 2010;60(4):427-43.

24. Guns S, Dereymaker A, Kayaert P, Mathot V, Martens JA, Van DMG. Comparison between hot-melt extrusion and spray-drying for manufacturing solid dispersions of the graft copolymer of ethylene glycol and vinylalcohol. Pharm Res. 2011;28(3):673-82.

25. Thakral NK, Ray AR, Bar-Shalom D, Eriksson AH, Majumdar DK. SoluplusSolubilized Citrated Camptothecin-A Potential Drug Delivery Strategy in Colon Cancer. AAPS Pharm Sci Tech. 2012;13(1):59-66.

Cite this article: Dukhan AAM, Amalina N, Oo MK, Sengupta P, Doolaanea AAM, Aljapairai KAS, Chatterjee B. Formulation of Dispersed Gliclazide Powder in Polyethylene Glycol-Polyvinyl Caprolactam-Polyvinyl Acetate Grafted Copolymer Carrier for Capsulation and Improved Dissolution. Indian J of Pharmaceutical Education and Research.2018;52(4 Suppl 2):s210-s219. 


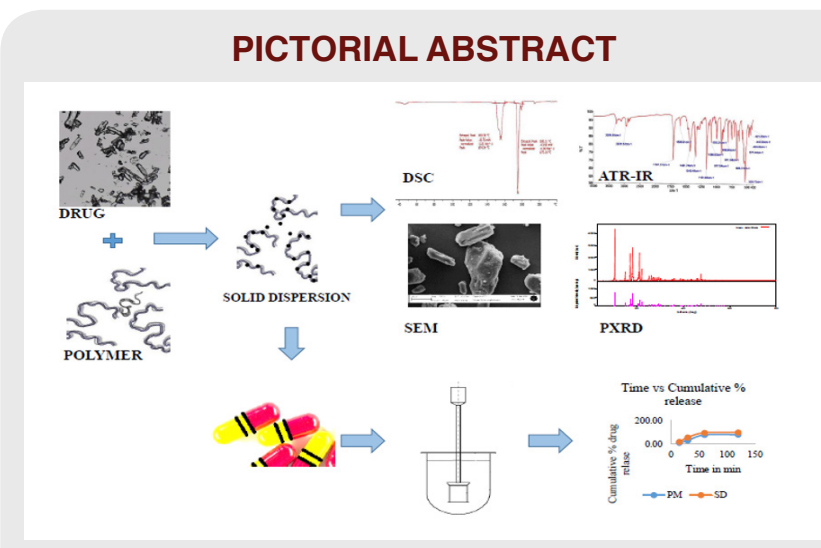

\section{SUMMARY}

Gliclazide solid dispersion in Polyethylene glycol-polyvinyl caprolactam-polyvinyl acetate grafted copolymer (Soluplus ${ }^{\circledR}$ ) carrier was prepared by solvent evaporation method. Optimum formulation was developed in 1:8 weight ratio of gliclazide: Soluplus ${ }^{\circledR}$. Developed solid dispersed powder was capsulated which resulted in improved dissolution in acidic and basic $\mathrm{pH}$ medium

\section{About Authors}

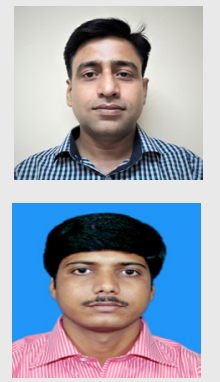

Bappaditya Chatterjee, a Ph.D from Jadavpur University, India and currently attached to the Dept. of Pharm. Tech., IIUM, Malaysia as an Assistant Professor. He has 8 years of experience in academic and industry based research and published several articles in high impact international journals of pharmaceutical sciences.

Ms. Ather Ahmed Mahdi Dukhan completed her Bachelor in Pharmacy from International Islamic University Malaysia (IIUM) with grade ' $A$ ' in the year of 2017. At present she is pursuing Master in Pharmacy in IIUM, Malaysia.

Ms. Nursazreen Amalina completed her Bachelor in Pharmacy from International Islamic University Malaysia (IIUM) with grade ' $A$ ' in the year of 2017. At present she is doing pre-registration pharmacist job attachment.

Ms. May Kyaw Oo, after successful completion of her bachelor followed by Master Degree from International Islamic University Malaysia in the year of 2016 at present Ms. May is pursuing PhD degree. She has published article of solid dispersed formulation in high impact journals.

Khater Ahmed Saeed Aljapairai, pharmacy graduate from Yemen is currently pursuing Master in Pharmacy at IIUM, Malaysia. Mr. Khater has several years of experience as a practicing pharmacist. 